\title{
ПРОБЛЕМА РАЗРУШЕНИЙ НА БОСПОРЕ \\ КОНЦА VI - НАЧАЛА V ВВ. ДО Н.Э. И БОСПОРО-АХЕМЕНИДСКИЙ ВОПРОС
}

\author{
(C2020 г. К. С. Лазарева
}

В статье рассматривается проблема взаимосвязи разрушений на Боспоре конца VI - начала V вв. до н.э. с персидскими военными походами в Северное Причерноморье. Традиционно данные разрушения связывались со скифскими набегами, при этом одним из аргументов сторонников этой версии было присутствие в слоях разрушений наконечников стрел скифского типа. Недавно была выдвинута иная версия, согласно которой причиной разрушений стали военные действия со стороны персов. Однако, скифские наконечники стрел, как и скифский лук, использовались не только скифами и персами, но также и греками. Вследствие этого аргументация исследователей, которые выступают за возможность персидского протектората над Боспором, выглядит весьма сомнительно. Автором делается вывод, что на основании наличия в археологических слоях, фиксирующих череду разрушений в полисах Боспора, наконечников скифского типа нельзя делать выводы относительно того, кто являлся виновником этих разрушений. Следует признать, что на сегодняшний день обнаружение наконечников стрел скифского типа в слоях разрушений на Боспоре не может быть серьезным аргументом в дискуссии о существовании персидского протектората над Боспором в конце VI - начале V вв. до н.э.

Ключевые слова: археология, Боспор, Ахеменидская империя, скифы, скифский лук, скифские наконечники стрел, Персия.

\section{THE ISSUE OF DESTRUCTIONS ON BOSPORUS IN LATE $6^{\mathrm{TH}}-$ EARLY $5^{\mathrm{TH}}$ CENTURIES BC AND RELATIONS BETWEEN THE BOSPORUS AND THE ACHAEMENIDS}

\section{K.S. Lazareva}

The article addresses the issue of the correlation of destructions on the Bosporus in the late $6^{\text {th }}-$ early $5^{\text {th }}$ centuries BC with Persian military campaigns into North Black Sea. Traditionally, these destructions were connected with the Scythians raids, and one of the arguments of the supporters of this theory was the presence of Scythian type arrowheads in the destruction layers. Recently, a new version has appeared, according to which the cause of these destructions in the Bosporus cities was Persian military activity. However, not only the Scythians or Persians used Scythian arrowheads as well as the Scythian bow, as this weaponry also was utilized by the Greeks. Therefore, the argumentation of those scholars who support the idea that the Bosporus was under Achaemenids appears rather quite controversial. According to author's opinion, it is impossible to draw conclusions as to who was responsible for the damage based on the presence of Scythian type arrowheads in the archaeological strata, fixing the series of destructions in the Bosporus city-states. It should be recognized that at the moment the presence of Scythian type arrowheads cannot be regarded as a substantial point in the discussion concerning the existence of the Persian rule over the Bosporus in the late $6^{\text {th }}$ - early $5^{\text {th }}$ centuries BC.

Keywords: archaeology, Bosporus, Achaemenid Empire, Scythians, Scythian bow, Scythian arrowheads, Persia.

В последнее время все чаще появляются работы, посвященные проблеме боспороперсидских взаимодействий. Взгляды исследователей на данный вопрос кардинально расходятся. Одни ученые придерживаются версии, согласно которой Боспор входил в сферу влияния Ахеменидской державы и даже находился под ее протекторатом (Fedoseev, 1997; Кошеленко, 1999; Яйленко, 2004; Nieling, 2010; Федосеев, 2014; Цецхладзе, 2014; Кузнецов, 2018; Tsetskhladze 2018, 2019). Другие же категорически отрицают такую

возможность в связи с отсутствием прямых свидетельств (Молев, 2001, 2016, 2017; Балахванцев, 2018). Третьи занимают осторожную позицию (Treister, 2010; Трейстер, 2011; Завойкин, 2015; Рунг, Габелко, 2018). В связи с открытием в Фанагории фрагмента клинописного памятника на древнеперсидском языке в 2016 г. интерес исследователей к данной теме еще больше усилился.

В ходе работы по изучению возможности ахеменидского присутствия на берегах Боспора в период греко-персидских войн 
мы столкнулись и с вопросом о разрушениях на данной территории, относящихся ко второй половине VI - первой трети V вв. до н. э. Обычно в отечественной историографии разрушения трактовались как следствие либо скифской агрессии (Блаватский, 1954, с. 39; Толстиков, 1984; Шелов-Коведяев, 1985, с. 65-67; Виноградов, Тохтасьев, 1994, с. 56-57; Виноградов, 2005, с. 241), либо межгреческих конфликтов (Долгоруков, 1990, с. 35; Масленников, 1996; Молев, 2017, с. 30-34; Сапрыкин, 2013), однако возможна и третья версия - персидская, предложенная Й. Нилингом и поддержанная Г.Р. Цецхладзе. Цель работы: выяснить, можно ли считать причиной разрушений на Боспоре военные действия персов, как предположил Й. Нилинг?

Рубеж VI-V вв. до н. э. на Боспоре является временем военной напряжённости и дестабилизации, о чем свидетельствуют множество разрушений и следы пожаров как в полисах европейской части, так и азиатской. Можно говорить о наличии данных слоев в: Нимфее, недалеко от Нимфея в пос. Героевское, Тиритаке, Зенонове Херсонесе (на мысе Зюк), Пантикапее, Порфмии, Парфении, Мермекии, Патрее, Фанагории, и Кепах. Возводятся оборонительные сооружения в Тиритаке (т. н. «Тиритакский вал»), Мирмекии и Фанагории. В это же время, в 480/79 гг. до н. э., к власти на Боспоре, по сообщению Диодора (Diod., XII. 31. 1), приходят Археанактиды. Эти два факта многие исследователи связывают друг с другом - наличие военной опасности послужило причиной складывания «симмахии» под руководством Археанактидов. Однако возникает вопрос, кто был этой опасностью скифы или персы?

Одной из характерных черт разрушений является наличие предметов вооружения в археологических слоях того времени. Нас же больше всего интересуют наконечники стрел, определяемые обычно как скифские. Так, в Тиритаке в слое пожара, датируемом VI в. до н. э., обнаружены бронзовые наконечники стрел (Зинько, 2013, с. 186), в той же Тиритаке, но уже в слое конца первой четверти V в. до н. э. во дворе одной из усадьб найдено около полутора десятка бронзовых наконечников стрел, открытых in situ в кладке построек (Зинько, 2013, с. 188). В Мирмекии в слое конца первой трети V в. до н. э. вновь обнаруживается немалое количество бронзовых трехлопастных наконечников стрел скифских типов, т. н. «базисных», которые по датировке
А.И. Мелюковой относятся ко второй половине VI - первой половине V вв. до н. э. Один из наконечников деформирован от удара о твердый предмет (Виноградов, Тохтасьев, 1994, c. 58). В Пантикапее в слое пожарища 480 г. до н. э. обнаружено около 20 наконечников, торчащих в сырцово-каменных стенах одного из зданий (Зинько, 2013, с. 188). Наконечники данного типа во многих исследованиях обычно соотносят со скифами, то есть наконечники, таким образом, выступают своеобразным индикатором определения скифской причины разрушений. Однако со всей определенностью, на основании вышеперечисленных данных, можно заключить лишь то, что на Боспоре в это время существовала военная напряженность, о чем свидетельствуют следы пожаров и разрушения.

Рассмотрим все возможные варианты причин этих разрушений. Многие исследователи являются сторонниками скифской причины, то есть той, где скифы являются виновниками этих вышеупомянутых событий. Одним из важнейших фактов в истории греческих поселений Северного Причерноморья является соседство с местными, обитающими в данном ареале, варварскими племенами. Сторонники скифской причины считают, что расширение границ греческой ойкумены не могло не привести к столкновению интересов двух сторон. В частности, в конце VI - начале $\mathrm{V}$ вв. до н. э. происходят радикальные изменения в скифском мире. В.П. Толстиков, вслед за Ю.Г. Виноградовым (Виноградов, 1989, с. 81), катализатором этих процессов называет скифский поход Дария I, закончившийся неудачей персов и победой объединенных скифских племен. Победа стала своего рода отправной точкой экспансии, в конечном счете дошедшей и до Боспора (Толстиков, 1984, с. 25).

Вот основные доказательства сторонников скифской причины: 1) сообщение Геродота о переходах скифов через Боспор зимой (Hdt., IV, 28); 2) археологическое свидетельство - сооружение Тиритакского вала (либо его реконструкция), датируемого 80-70 гг. V в.; 3) отсутствие оборонительных стен греческих поселений в VI в. до н. э., а затем появление их в V в. до н. э. в Тиритаке, Мирмекии и Фанагории. Разрушения прослеживаются, как уже было сказано выше, во многих полисах Боспора, существовавших в то время. Данные аргументы хорошо вписываются в теорию Ю.Г. Виноградова, который говорил о создании «единой военно-оборонительной симмахии 
и одновременно религиозной амфиктионии вокруг Пантикапея и его главного святилища Аполлона» (Виноградов, 1989, с. 90) перед лицом скифской угрозы.

Еще одной версией разрушений является возможность внутренней борьбы между греческим населением. В частности, В.C. Долгоруков в отличие от «скифской» причины объединения полисов на Боспоре (которую он относил к числу предпосылок) называл основной социальную борьбу апойков и эпойков за перераспределение клеров и их политические права, закончившуюся консолидацией Боспора под властью Археанактидов (Долгоруков, 1990, с. 35-36).

Сторонником условно «внутренних» причин объединения выступал А.А. Масленников (Масленников, 1996), который не считает скифскую угрозу доминирующей в вопросе объединения Босопра. Наоборот, он говорит, что основные пространства, которые могли бы быть необходимы скифам, не были по существу ограничены греческим населением (что характерно для начала IV в.). А упоминание Геродотом перехода скифами Боспора можно трактовать как договоренность между скифами и греками. Е.А. Молев же предполагает, что разрушения произошли после того, как «малые полисы» Боспора - Мирмекий, Тиритака и Порфмий, достигнув определенного развития, попытались добиться автономии, за что были наказаны Пантикапеем (Молев, 2017. с. 30-34).

Относительно недавно появилась и еще одна точка зрения по данному вопросу. Йенс Нилинг подверг сомнению «скифскую» причину разрушений. Он считает неправдоподобным данное утверждение в силу того, что сильное скифское руководство предпочло бы контролировать неповрежденные греческие торговые посты, а не разрушать источник, обеспечивающий их предметами роскоши и др. (Nieling, 2010, p. 129). Подобно слою афинского акрополя и агоры, Нилинг предлагает назвать слой разрушений на Боспоpe «Персидским мусором» («Perserschutt»). Поскольку следы бедствий, как ему представляется, были ограничены преимущественно крупными и средними городскими центрами, не затрагивая территории хоры, Нилинг говорит о том, что, вероятно, противник пришел с моря и был заинтересован в разрушении крупных сооружений, нежели в разорении сельских поселений. В конце рассуждений он пишет: «По моему мнению, это скорее похоже на следы действий организованных военноморских сил, чем на следы набегов конницы кочевников или войск разъяренных соседей» (Nieling, 2010, р. 130). Нилинг, таким образом, исключает скифский фактор, выдвигая ему на смену персидский.

Независимо от Й. Нилинга схожие предположения относительно персидской причины разрушений высказал В.Н. Зинько в 2013 году. Однако Зинько указывает на то, что было несколько «волн» этих разрушений, которые происходили с периодичностью в несколько десятилетий, и не исключает того, что причины для каждой из них могли быть разные. Так, последнюю - третью (конец первой четверти VI в. до н. э.) он с большой уверенностью связывает со скифами, а две другие (середины и конца VI в. до н. э.), по его мнению, возможно следует связать с персидскими походами к Северному Причерноморью. Тем не менее он не делает никаких далеко идущих выводов по вопросу ахеменидского протектората над Боспорским царством или зависимости этих территорий от персов, так как письменные источники, которые могли бы осветить данную проблему, отсутствуют, а археологические говорят только о последствиях военных конфликтов (Зинько, 2013, с. 190-191).

Многое в теории Нилинга является преувеличенным, однако в одном из положений мы с ним согласимся - в том, что на основе только археологического материала, такого как оружие, определить реального врага невозможно: «Любой персидский сатрап из Восточной Анатолии вполне мог бы быть ответственен за эти разрушения, даже если он отправил греков с южного побережья Черного моря или негреческие понтийские силы сделать свою грязную работу. Если персы были ответственны, невозможно будет определить реального врага на Боспоре только по археологическому материалу, такому как оружие» (Nieling, 2010, p. 134).

Именно поэтому весьма сомнительно выглядит утверждение Г.Р. Цецхладзе, который в недавно опубликованной работе, оперируя фактом идентичности наконечников стрел у скифов и персов, пришел к выводу, что наконечники, найденные на Боспоре в слоях разрушений, принадлежат не скифам, a персам (Tsetskhladze, 2019, p. 127). Заметим, что Цецхладзе идет еще дальше в своих рассуждениях относительно вопроса протектората над Боспором и связывает разрушения с установлением власти персов над Боспором. 
Он также расширяет границы Ахеменидской империи, включая туда и Боспор и Колхиду, делая таким образом Черное море «Персидским озером» («Persian Lake») (Tsetskhladze, 2019, p. 145). Мы в корне не согласны ни с выводами Г.Р. Цецхладзе, ни с его аргументами. Остановимся на одном из них, касающемся определения принадлежности наконечников скифского типа персам.

Многие исследователи, ссылаясь на присутствие в археологическом контексте наконечников стрел (определяя их как скифские) в слоях разрушений, интерпретировали данный факт, как доказательство вины кочевников. Однако вопрос заимствований вооружения является очень сложным. В случае с наконечниками стрел и в контексте интересующего нас вопроса можно говорить о нескольких вариантах того, кто мог бы их использовать. Во-первых, это использование их собственно скифами против греков, во-вторых, использование греками против друг друга, и, в-третьих, действительно нельзя исключить, что наконечники принадлежат не скифам, а персам.

В первом и втором случаях картина представляется более или менее ясной. После заселения данных территорий греки, столкнувшись, во-первых, с совершенно другой тактикой ведения войны, а во-вторых, с ландшафтно-географическими особенностями данной территории, видимо, отказались от традиционного метода ведения войны и оружия, поскольку использование полной гоплитской паноплии оправдано только в условии фалангового боя. Скорее всего, после первых столкновений колонисты опытным путем убедились в неэффективности своей тактики и вооружении, поэтому вынуждены были заимствовать вооружение кочевников, в том числе и знаменитые скифские луки. Археологически подтверждено, что в Пантикапее работал оружейник, изготовлявший предметы скифского вооружения. Весьма интересен вопрос, делал ли он это для скифов или для греческого населения? Вероятно, что для обеих сторон (Марченко, 1971).

В случае со сравнением персидских и скифских наконечников стрел проблема идентификации принадлежности наконечников комуто из двух народов является также сложной. Персы, главным оружием которых был также лук, заимствовали его у скифов (Дандамаев, Луконин, 1980, с. 231), предположительно через мидийцев (Медведкова, 1980, с. 34). На рельефе из дворца Дария I в Сузах (ок. 490 гг. до н. э.) у изображенной персидской гвардии мы можем увидеть луки «скифского» типа (Медведкова, 1980, с. 34).

В течение VII-VI вв. скифские луки распространились по Западной Азии, а вместе с ними и наконечники стрел тех же типов, что и скифские, которые были обнаружены в Кархемише, Ниневии, Ашшуре, Вавилоне и др. (Dandamaev, 1992, p. 160). В Греции «скифские» наконечники появляются в конце VI - начале V вв. до н. э. Так, например, они были найдены в Олимпии, Афинах, Дельфах и др. Собственно, греческих наконечников в самой Греции очень мало, многие из них относятся к Бронзовому веку. Для архаического и классического периодов характерны два типа - критские и скифские. Как пишет А.Д. Тодд: «В конечном счете выясняется, что ни один наконечник не может считаться типично греческим... Большинство найденных наконечников относятся к критскому и скифскому типам, но следует подчеркнуть, что этот факт не является доказательством критского или скифского присутствия» (Todd, 2013, p. 10).

Скифские наконечники присутствуют и там, где скифы исторически не засвидетельствованы (как, например, в Вавилоне и Египте) (Дандамаев, Луконин, 1980, с. 232). Весьма показательна подборка ареала распространения наконечников, сделанная Тодеушем Сулимирским. Скифские наконечники встречаются также на Сицилии, в Южной Италии, на Сардинии, на территории современной Польши, Германии, Австрии, бывшей Югославии, несколько экземпляров было найдено даже в Бельгии и во Франции (Sulimirski, 1954, p. 296-308). Однако данные территории, несмотря на наличие наконечников скифского типа, не входили в территории расселения скифских племен. Исторически не засвидетельствовано здесь и присутствие персов.

Таким образом, исходя из всего вышесказанного, нам представляется весьма сложным определить принадлежность наконечников конкретно кому-то из двух народов. Двуперые, с шипом сбоку или же трехгранные наконечники, совпадающие по форме со скифскими (Пиотровский, 1959, с. 238), или, как пишет М.В. Горелик, втульчатые, двух-, а затем трехлопастной и пирамидальной формы связаны с использованием лука «скифского» типа, поэтому присутствие таких наконечников в археологическом комплексе «автоматически свидетельствует о том, что носители этой 
культуры применяли лук «скифского» типа» (Горелик, 1993, с. 73).

Сделать вывод касательно вопроса о том, принадлежали ли наконечники скифам или персам, как нам кажется, нельзя. Можно лишь говорить о том, что нападавшие имели луки скифских типов. Следовательно, наличие наконечников скифского типа в слоях разрушений еще не говорит о том, что скифы были их виновниками. Тем не менее и говорить о том, что причиной разрушения греческих поселений на Боспоре были персы, как считает Й. Нилинг, а вслед за ним и Г.Р. Цецхладзе, по нашему мнению, нельзя, т. к. сами теории строятся на достаточно спорных аргументах и косвенных свидетельствах. Сомнительным выглядит этот факт и потому, что хронологический разброс разрушений составляет около полувека. Все это вызывает некоторые вопросы. Неужели персы в течение полувека находились на Боспоре либо снаряжали каждые 10-20 лет экспедиции в (основанные не так давно) полисы? Главный же вопрос (если все же допустить такую возможность) - чем были мотивированы персидские действия на Боспоре. Не стоит также забывать о том, что разрушения были связаны не с одной единовременной акцией, а чередой событий, продолжающихся в течение полувека. И причины в разное время могли быть совершенно отличные в каждом конкретном случае.

Возможно, стоит попытаться провести специальный анализ наконечников, как найденных в слоях разрушений, так и распространенных на территории проживания скифов, и сравнить их с наконечниками, найденными в тех местностях, которые безоговорочно определяются как персидские. На данный же момент теория, где виновниками разрушений на Боспоре выступают персы, остается лишённой серьезной аргументации, вследствие чего версии, где причиной выступает либо скифская агрессия, либо межгреческие конфликты, на наш взгляд, выглядят более правдоподобно. Отсюда следует, что вопрос о присутствии в археологических слоях разрушений на Боспоре наконечников определенного типа на сегодняшний момент не может служить серьезным аргументом в споре о наличии или отсутствии персидского протектората на Боспоре в конце VI - начале V вв. до н. э.

\section{ИСТОЧНИКИ И ЛИТЕРАТУРА}

Балахваниев А.С. Боспор и Ахемениды // Материалы Междун. науч. конф. «Боспорский феномен. Общее и особенное в историко-культурном пространстве античного мира»(Санкт-Петербург, 28 - 30 ноября 2018). Ч. І / Отв. ред. В. Ю. Зуев, В.А. Хршановский. СПб.: ИПЦ СПбГУПТД, 2018. С. 61-65.

Блаватский В.Д. Архаический Боспор // Материалы и исследования по археологии Северного Причерноморья в античную эпоху. Т. ІІ. / МИА. № 33 / Отв. ред. М.М. Кобылина. М.: Изд-во АН СССР, 1954. C. 7-44.

Виноградов Ю.А. Боспор Киммерийский // Греки и варвары Северного Причерноморья в скифскую эпоху / Отв. ред. К.К. Марченко. СПб.: Алетейя, 2005. С. 211-296.

Виноградов Ю.А., Тохтасьев С.Р. Ранняя оборонительная стена Мирмекия // ВДИ. 1994. № 1. С. $54-63$.

Виноградов Ю.Г. Политическая история Ольвийского полиса VII-I вв. до н.э. Историко-эпиграфическое исследование. М.: Наука, 1989. 288 с.

Горелик М.В. Оружие древнего Востока (IV тысячелетие IV в.до н.э.) М.: Восточная литература, 1993. $352 \mathrm{c}$.

Дандамаев М.А., Луконин В.Г. Культура и экономика древнего Ирана. М.: Наука, 1980. 416 с.

Долгоруков В.С. Некоторые вопросы истории и топографии ранней Фанагории // КСИА. 1990. Вып. 197. C. 30-37.

Завойкин А.А. Ахемениды и Боспор (историографический аспект проблемы) // Проблемы истории, филологии, культуры (ПИФК). 2015. №. 1(47). С. 240-261.

Зинько В.Н. Позднеархаическая история европейского Боспора в свете новейших археологических исследований // Проблемы истории, филологии, культуры (ПИФК). 2013. № 2(40). С. 183-193.

Кошеленко Г.А. Об одном свидетельстве Диодора о ранней истории Боспорского царства. // Древние государства Восточной Европы 1996-1997 гг. / Отв. ред. А.В. Подосинов. М., 1999. С. 130-141.

Кузнецов В.Д. Боспор Киммерийский в 5 в. до н. э. (древнеперсидская надпись из Фанагории) // Фанагория. Результаты археологических исследований / Отв. ред. В. Д. Кузнецов. М.: Институт археологии РАН, 2018. Том 6, вып. 3. С. 160-185. 
Марченко И.Д. Архаическая мастерская оружейника в Пантикапее // СА. 1971. № 2. С. 148-156.

Масленников А.А. Некоторые проблемы ранней истории Боспорского государства в свете новейших археологических исследований в Восточном Крыму // Проблемы истории, филологии, культуры (ПИФК). 1996. № 3. С. 61-71.

Медведкова И.Н. Металлические наконечники стрел Переднего Востока и евразийских степей II первой половины І тыс. до н. э. // СА. 1980. № 4. С. 23-37.

Молев E.A. О возможности персидского протектората над Боспором (по поводу статьи: Федосеев, 1997) // Материалы Междун. науч. конф. «Боспорский феномен: Колонизация региона, формирование полисов, образование государства» (Санкт-Петербург, 2-12 декабря 2001 г.) / Отв. ред. В.Ю. Зуев. СПб.: Изд-во Гос. Эрмитажа, 2001. С. 29-33.

Молев Е.А. К вопросу о вероятности подчинения Боспора персам // Боспорские исследования / Отв. ред. В. Н. Зинько. Керчь: Керченская городская типография. 2016. Вып. XXXIII. С. 17-27.

Молев Е.А. Боспорские древности. Проблемы политической, социальной и культурной истории античного Боспора. Нижний Новгород: Изд-во Нижегородского госуниверситета, 2017. 340 с.

Пиотровский Б.Б. Ванское царство (Урату). М.: Издательство восточной литературы, 1959. 286 с.

Рунг Э.В., Габелко О.Л. Скифский поход Дария I и древнеперсидская надпись из Фанагории // ВДИ. 2018. №4. С. $847-869$.

Сапрыкин С.Ю. Археанактиды и градостроительство // Боспорские исследования Вып. XXVIII / Отв. ред. В. Н. Зинько. Симферополь-Керчь, 2013.. С. 21-46.

Толстиков В.П. К проблеме образования Боспорского государства (Опыт реконструкции военнополитической ситуации на Боспоре в конце VI - первой половине V в. во н.э.) // ВДИ. 1984. № 3. C. 24-47.

Трейстер М.Ю. Ахеменидские «импорты» на Киммерийском Боспоре. Анализ и интерпретация // Материалы Междун. науч. конф. «Боспорский феномен. Население, языки, контакты» (СанктПетербург, 22-25 ноября 2011 г.) / Ред. М.Ю. Вахтина и др. СПб: Нестор-История, 2011. С. 113-121.

Федосеев Н.Ф. Некоторые дискуссионные вопросы организации и развития Боспорского государства // Древние государства Восточной Европы 2012: Проблемы эллинизма и образования Боспорского царства / Отв. ред. А.В. Подосинов, О.Л. Габелко. М.: Русский Фонд Содействия Образованию и Науке, 2014. C. $154-158$.

Цецхладзе Г.Р. Боспорское царство: особенности образования и развития // Древние государства Восточной Европы 2012: Проблемы эллинизма и образования Боспорского царства / Отв. ред. А.В. Подосинов, О.Л. Габелко. М.: Русский Фонд Содействия Образованию и Науке, 2014. С. 213-220.

Шелов-Коведяев Ф.В. История Боспора VI-IV вв. до н.э. // Древнейшие государства на территории СССР. Материалы и исследования. 1984 г. М.: Наука, 1985. С. 5-187.

Яйленко В.П. Военная акция Дария I на Киммерийском Боспоре // Материалы Междун. науч. конф. «Боспорский феномен: проблемы хронологии и датировки памятников» (Санкт-Петербург, 2004 г.) Ч. I. / Отв. ред. В. Ю. Зуев. СПб.: ГЭ 2004. С. 55-60.

Dandamayev M.A. Iranians in Achaemenid Babylonia / Columbia Lectures on Iranian Studies. No. 6. Costa Mesa, New York: Mazda Publishers in association with Bibliotheca Persica, 1992. 258 p.

Fedoseev N. Zum achämenidischen Einfluß auf die historische Entwicklung der nordpontischen griechischen Staaten // Archäologische Mitteilungen aus Iran und Turan. 1997. № 29. P. 309-319.

Nieling J. Persian Imperial Policy Behind the Rise and Fall of the Cimmerian Bosporus in the Last Quarter of the Sixth to the Beginning of the Fifth Century BC // Achaemenid Impact in the Black Sea. Communication of Power (Black Sea Studies 11) / Eds. J. Nieling, E. Rehm. Aarhus, 2010. P. 123-136.

Sulimirski T. Scythian Antiquities in Western Asia // Artibus Asiae. 1954. Vol. 17. No. 3/4. P. 296-308.

Todd A. D. Archery in Archaic Greece. PhD. New York: Columbia University. 2013.

Treister M. «Achaemenid» and «Achaemenid-inspired» Goldware and Silverware, Jewellery and Arms and their Imitations to the North of the Achaemenid Empire // Achaemenid Impact in the Black Sea. Communication of Power (Black Sea Studies 11) / Eds. J. Nieling, E. Rehm. Aarhus, 2010. P. 223-279.

Tsetskhladze G.R. Darius Crossing the Sea. The Achaemenid Factor in the Bosporan Kingdom // История античного мира и средневековья в университетах Украины. К 40-летию кафедры истории древнего мира и средних веков ХНУ имени В. Н. Каразина. Тезисы докладов Международной научной конференции (Харьков, 25-26 октября 2018 г.) / Отв. ред. С. В. Дьячков. Харьков: ООО «НТМТ», 2018. C. 71-76. 
Tsetskhladze G.R. An Achaemenid Inscription from Phanagoria: Extending the Boundaries of Empire // Ancient West \& East. 2019. Vol. 18. P. 113-151.

\section{Информация об авторе}

Лазарева Карина Сергеевна, Самарский национальный исследовательский университет имени академика С.П. Королева (г. Самара, Россия); lazareva.istfac@gmail.com

\section{REFERENCES}

Balakhvanstev, A. S. 2018. In Zuev, V. Yu., Khrshanovski, V. A. (eds.). Materialy Mezhdunarodnoi nauchnoi konferentsii "Bosporskii fenomen. Obshhee i osobennoe v istoriko-kul turnom prostranstve antichnogo mira" (Sankt-Peterburg, 28-30 noiabria 2018 g.) (Proceedings of International Research Conference "Bosporus phenomenon. General and Special within the Historical and Cultural Space of the Ancient World" (Saint Petersburg, November 28-30, 2018)). Saint Petersburg: Saint Petersburg State University of Industrial Technologies and Design Publ., 61-65 (in Russian).

Blavatsky, V. D. 1950. In Kobylina, M. M. (ed.) Materialy po arkheologii Verkhnego Povolzh ya (Materials and Studies on the Archaeology of the Northern Black Sea Region in the Ancient Era) II. Series: Materialy i issledovaniia po arkheologii SSSR (Materials and Studies in Archaeology of the USSR) 33. Moscow: Academy of Sciences of the USSR Publ., 7-44 (in Russian).

Vinogradov, Yu. A. 2005. In Marchenko, K. K. (ed). Greki i varvary Severnogo Prichernomor'ya v skifskuyu epokhu (The Greeks and Barbarians of the Northern Black Sea Region in the Scythian Era). Saint Petersburg: "Aleteiia" Publ. (in Russian).

Vinogradov, Yu. A., Tokhtas'ev, S. R. 1994. In Vestnik drevnei istorii (Journal of Ancient History) 1. 54-63 (in Russian).

Vinogradov, Yu. G. 1989. Politicheskaia istoriia Ol'viiskogo polisa VII-I vv. do n.e. Istoriko-epigraficheskoe issledovanie (Political History of the Olbian Polis of the 7th-1st cc. BC. Historical and Epigraphic Study). Moscow: "Nauk" Publ. (in Russian).

Gorelik, M. V. 1993. Oruzhie drevnego Vostoka (IV ty 'syacheletie IV v.do n.e '.) (Armament of the Ancient East (4th Millennium, $4^{\text {th }}$ Century BC)). Moscow: "Vostochnaia literatura" Publ., 149-178 (in Russian).

Dandamaev, M. A., Lukonin, V. G. 1980. Kul'tura i ekonomika drevnego Irana (Culture and Economy of Ancient Iran). Moscow: "Nauka" Publ. (in Russian).

Dolgorukov, V. S. 1990. In Kratkie soobshcheniia Instituta arkheologii (Brief Communications of the Institute of Archaeology) 197, 30-37 (in Russian).

Zavoykin, A. A. 2015. In Problemy istorii, filologii, kul'tury (Journal of Historical, Philological and Cultural Studies) 47 (1), 240-261 (in Russian).

Zin'ko, V. N. 2013. In Problemy istorii, filologii, kul'tury (Journal of Historical, Philological and Cultural Studies) 40 (2), 183-193 (in Russian).

Koshelenko, G. A. 1999. In Podosinonov, A. V. (ed.). Drevneishie gosudarstva Vostochnoi Evropy. 19961997 (The Earliest States of Eastern Europe: 1996-1997). Moscow: "Nauka" Publ., 130-141. (in Russian).

Kuznetsov, V. D. 2018. In Kuznetsov, V. D. (ed.). Fanagoriia. Rezultaty arkheologicheskikh issledovaniy (Phanagoria. Archaeological Study Results) 6(3), 160-185 (in Russian).

Marchenko, I. D. 1971. In Sovetskaya arkheologiya (Soviet Archaeology) 2. 148-156 (in Russian).

Maslennikov, A. A. 1996. In Problemy istorii, filologii, kul'tury (Journal of Historical, Philological and Cultural Studies) 3, 61-71 (in Russian).

Molev, E. A. 2001. In Zuev, V. Yu. (ed.). Materialy Mezhdunarodnoi nauchnoi konferentsii "Bosporskii fenomen. Naselenie, iazyki, kontakty" (Sankt-Peterburg, 2-12 dekabrya 2001 g.) (Proceedings of International Research Conference (Bosporan Phenomenon. Colonization of the Region, Creation of Policies, Formation of the State) (Saint Petersburg, December 22-25, 2001)). Saint Petersburg: "Nestor-Istoriia" Publ., 29-33 (in Russian).

Molev, E. A. 2016. In Zinko, V. N. (ed.). Bosporskie issledovaniia (Bosporan Studies) XXXIII. Simferopol; Kerch, 17-27. (in Russian).

Molev, E. E. 2017. Bosporskie drevnosti. Problemy politicheskoi i kul'turnoi istorii antichnogo Bospora (Bosporus Antiquities. Issues of Political, Social and Cultural History of Ancient Bosporus). Nizhniy Novgorod: Nizhny Novgorod State University Publ. (in Russian).

Piotrovskiy, B. B. 1959. Vanskoe tsarstvo (Urartu) (Kingdom of Van (Urartu)). Moscow "Izdatel'stvo vostochnoi literatury" Publ. (in Russian). 
Rung, E. V., Gabelko, O. L. 2018. In Vestnik drevnei istorii (Journal of Ancient History) 4, 847-869 (in Russian).

Saprykin, S. Yu. 2013. In Zinko, V. N. (ed.). Bosporskie issledovaniia (Bosporan Studies) XXVIII. Simferopol; Kerch, 21-46. (in Russian).

Tolstikov, V. P. 1984. In Vestnik drevnei istorii (Journal of Ancient History) 3. 24-47 (in Russian).

Treister, M. Yu. 2011. In Vakhtina, M. Yu., et al. (eds.). Materialy Mezhdunarodnoi nauchnoi konferentsii "Bosporskii fenomen. Naselenie, iazyki, kontakty" (Sankt-Peterburg, 22-25 noiabria 2011 g.) (Proceedings of International Research Conference (Bosporan Phenomenon. Population, Languages and Contacts) (Saint Petersburg, November 22-25, 2011)). Saint Petersburg: "Nestor-Istoriia" Publ., 113-121 (in Russian).

Fedoseev, N. F. 2014. In Podosinov, A. V., Gabelko, O. L. (eds.). Drevneyshie gosudarstva Vostochnoy Evropy. 2012. Problemy ellinizma i obrazovaniia Bosporskogo tsarstva (The Earliest States of Eastern Europe: 2012. Issues of Hellenism and the Formation of the Bosporus Kingdom). Moscow: "Russkiy fond sodeistviia obrazovaniyu i nauke" Publ., 154-158 (in Russian).

Tsetskhladze, G. R. 2014. In Podosinov, A. V., Gabelko, O. L. (eds.). Drevneyshie gosudarstva Vostochnoy Evropy. 2012. Problemy ellinizma i obrazovaniia Bosporskogo tsarstva (The Earliest States of Eastern Europe: 2012. Issues of Hellenism and the Formation of the Bosporus Kingdom). Moscow: "Russkiy fond sodeistviia obrazovaniyu i nauke" Publ., 213-220 (in Russian).

Chelova, N. L. 1983. In Sovetskaya arkheologiya (Soviet Archaeology) 1. 47-65 (in Russian).

Shelov-Kovedyaev, F. V. 1985. In Drevneishie gosudarstva na territorii SSSR. Materialy i issledovaniia 1984 g. (The oldest States on the territory of the USSR. Materials and Research 1984). Moscow: "Nauka" Publ. (in Russian).

Yailenko, V. P. 2004. In Zuev, V. Yu. (ed.). Materialy Mezhdunarodnoi nauchnoi konferentsii "Bosporskii fenomen: problemy khronogii i datirovki pamiatnikov (Sankt-Peterburg, 2004) (Proceedings of International Research Conference (The Phenomenon of Bosporan Kingdom: problems of chronology and dating) (Saint Petersburg, 2004)). Saint Petersburg: State Hermitage, 55-60 (in Russian).

Dandamayev, M. A. 1992. Iranians in Achaemenid Babylonia. Columbia Lectures on Iranian Studies. 6. Costa Mesa, New York: Mazda Publishers in association with Bibliotheca Persica.

Fedoseev, N. 1997. In Archäologische Mitteilungen aus Iran und Turan. No 29, 309-319. (in German).

Nieling, J. 2010. Persian Imperial Policy Behind the Rise and Fall of the Cimmerian Bosporus in the Last Quarter of the Sixth to the Beginning of the Fifth Century BC In J. Nieling, E. Rehm (eds.). Achaemenid Impact in the Black Sea. Communication of Power (Black Sea Studies 11) Aarhus, 123-136.

Sulimirski ,T. 1954. In Artibus Asiae. Vol. 17. No. 3/4, 296-308.

Todd, A. D. 2013. Archery in Archaic Greece. PhD. New York: Columbia University.

Treister, M. 2010. In Nieling, J., Rehm, E. (eds.). Achaemenid Impact in the Black Sea. Communication of Power (Black Sea Studies 11). Aarhus, 2010, 223-279.

Tsetskhladze, G. R. 2019. In Ancient West \& East. 18, 113-151.

Tsetskhladze, G. R. 2018. In D'yachkov, S. V. (ed.) Istorija antichnogo mira i srednevekov'ja v universitetah Ukrainy. (History of the Ancient World and the Middle Ages in the Universities of Ukraine). Kharkov; "NTMT" Publ., 71-76. (in English).

\section{About the Author:}

Lazareva Karina S., Samara National Research University named after academician S.P. Korolev. Moskovskoye shosse Str., 34, Samara, 443086, Russian Federation; lazareva.istfac@gmail.com 